\title{
Applications of Artificial Neural Networks in E-Learning Personalization
}

\author{
Rana Khudhair Abbas Ahmed \\ Alrafidain University \\ College/ Computer Techniques \\ Engineering Department \\ Iraq, Baghdad, Hay Amuatansiriya, \\ Falestenn street.
}

\begin{abstract}
Finding the most interested personalized learning materials is a difficult process for learners on the net. Artificial Neural Networks had proved to be a good help for users in finding their own personalized learning requirements from a large number of resources by giving suggestions to users and learners based on their preferences and all this with less time and effort. This paper discusses the importance of using neural networks in E-learning personalization and shows some current applications of them with their improvements and limitations.
\end{abstract}

\section{Keywords}

Neural networks, personalization, artificial intelligence, applications, e-learning.

\section{INTRODUCTION}

An artificial neural network (ANN) does not emulate the thought processes and if/ then logic of the human brain as done by an expert system. It mimics certain aspects of the information processing and physical structure of the brain with a web of neural connections. Therefore, some writers classified it as a "microscopic", "white-box" system and an expert system as a "macroscopic", "black-box" system [1].

Recently, e-Learning has become an active field of research and experimentation, with remarkable investments from all parts of the world. It represents the Web-based delivery of personalized, comprehensive, dynamic learning contents, aiding the development of communities of knowledge, linking learners and practitioners with experts. E-Learning supports the different phases of traditional learning and in some cases it is the only possible method of learning, allowing knowledge acquisition also in particular conditions (e.g. impaired students, absence of teaching structures, etc.). In this context, an important role is played by the definition of educational structure that must be contextualized and tailored on the basis of the requirements of: i) teachers, who have personal teaching approaches, and ii) students, who have personal studying approaches [2].

Personalized learning technological systems support learners to set their own learning goals, manage their learning, managing both content and process, communicate with others in the process of learning, and thereby achieve learning goals. These systems may be composed of one or more sub-systems which may in turn built on desktop based application or on web-based services [3].

\section{E-LEARNING}

E-learning is a delivery of learning, training or education programs by electronic means. It involves the use of a computer or electronic device in some way to provide training, educational or learning material. E-learning is the use of technology and services to deliver curricula and to facilitate learning. Delivering education in e-Learning is a tool used within each point of the education process and powerfully coordinates the organization. The following seven great reasons to use e-learning are: Scalable/Efficient and Fast, Capacity and consistency, Higher Learning Retention than traditional learning, E-Learning saves you time and money, Measuring learning activity and proving return on investment, Reduce your carbon footprint, Flexibility and finding hard to reach people [4].

The main advantage of e-Learning is the use of technology to enable people to learn anytime and anywhere. E-learning is more cost effective than traditional learning because less time and no travel expenses. The various types of e-learning are: means of communication, schedule, e-learning class structure, Technologies used [4].

\section{INTELLIGENT E-LEARNING SYSTEMS}

Artificial Intelligence (AI) utilizes programming algorithms to simulate thought processes and reasoning that produce behavior similar to humans. A successful implementation of AI could be tested using a Turing Test approach, in which a human interacts with an interface that could have either a human or computer on the other end. The test is considered successful if the human is unable to determine whether there is a computer or a human on the other end. The applications of AI within E-Learning can produce the potential of creating realistic environments with which students can interact. The student essentially would interact with the intelligent agents which in turn perceive changes in the simulated environment. The intelligent agents would then communicate perceived changes in the environment back to the student who then makes decisions based upon their own perceptions of the environment $[5,6]$. Current learning technologies can help create trained novices more efficiently, but they are really not up to the job of creating true experts [5].

\subsection{Evolution of $\mathrm{AI}$ in E-Learning}

Intelligent Tutoring Systems (ITS) - was founded by members of the AI community who had migrated to the educational community. Their motivation was as follow: "Research in AI is founded upon the conjecture that cognition is, in some sense, a computational process than can be studied through the construction of "intelligent" systems that serve as functional models of the otherwise inaccessible processes of the human mind. If machines can be programmed to display intelligent behavior, there is no reason, at least in principle, that systems could not be designed to assume the role of a skilled teacher $[5,7]$. 


\subsection{Neural Networks}

AI methods and techniques enable computer programs and software applications to think and act intelligently and rationally. To achieve this goal, AI utilizes methods and techniques, like: Neural Networks, Genetic Algorithms, Reinforcement Learning, and Fuzzy Logic [5].

Neural Networks do not rely on ruled-based programming for their performance. Instead, neural networks use learning algorithms to "tune" outputs to inputs. The technology finds use in situations in which rules are not explicitly available, and in which "tuning" inputs to outputs is easier than analyzing the internal reasoning process. Currently, data mining uses neural networks to analyze the large volumes of data $[5,8]$.

\section{PERSONALIZED E-LEARNING AND IT'S METHODS}

Personalized learning is the tailoring of pedagogy, curriculum and learning support to meet the needs and aspirations of individual learners. Data personalization is to facilitate the expression of the need of a particular user to enable him to obtain relevant information when he accesses an information system. The data describing the user's interests and preference is often gathered in the form of profile. One can identify business and /or ordinary customers, and monitors their behavioral profile over different providers through intelligent techniques. Personalization can also be achieved through navigate the documents of data sources, so that content is extracted from the Learning object repository [9]. There are two methods of personalization:

\section{Knowledge driven model for personalization}

E-learning solutions should be more than just a collection of technological solutions. Apart from sophisticated, stylish multimedia delivery, it should focus on enhancing the learning and intellectual interaction at the cognitive, behavioral, and physiological levels. Another impediment to the successful adoption of E-learning is the lack of learning personalization. The learner-centric aspect of E-learning is often neglected. All the learner has to do is to simply follow the prescribed paths through the whole courseware (dictated SME's subject matter experts) right from pre-assessment to post assessment. Another problem is that most of the courses are offered within the time frame of an academic semester, without consideration of the learners preferred pace and expertise [9].

\section{E-learning scenarios using two complementary personalization levels}

Personalization in an E-learning system can be achieved through two levels of personalization. Level 1 allows the personalization of learning contents and structure of the course according to a given personalization strategy and level 2 defines the personalization strategy. Teacher has to choose and apply the personalization strategy which matches the learner's characteristics and the specifics of the courses [9].

\section{CURRENTAPPLICATIONS OF ARTIFICIAL NEURAL NETWORKS IN E-LEARNING PERSONALIZATION}

Table (1) illustrates the current applications of neural networks in E-learning personalization since some last years.
Table 1, current applications of neural networks in elearning le

\begin{tabular}{|c|c|c|c|}
\hline SL No. & $\begin{array}{l}\text { Author } \\
\text { and year } \\
\text { of } \\
\text { Research }\end{array}$ & $\begin{array}{l}\text { Explanation of } \\
\text { Application }\end{array}$ & Limitations \\
\hline 1. & $\begin{array}{l}\text { Hassina } \\
\text { Seridi, } \\
\text { Toufik } \\
\text { Sari and } \\
\text { Mokhtar } \\
\text { Sellami, } \\
2006 .\end{array}$ & $\begin{array}{l}\text { The authors } \\
\text { used Artificial } \\
\text { Neural } \\
\text { networks for } \\
\text { generating } \\
\text { adaptive } \\
\text { lessons, their } \\
\text { work showed } \\
\text { the usefulness } \\
\text { of the } \\
\text { techniques } \\
\text { based on some } \\
\text { training, which } \\
\text { is considered } \\
\text { the main } \\
\text { drawback of } \\
\text { classical } \\
\text { methods [10]. }\end{array}$ & $\begin{array}{l}\text { The authors } \\
\text { proved their } \\
\text { work } \\
\text { efficiently on } \\
\text { their chosen } \\
\text { dataset with } \\
\text { different } \\
\text { Neural } \\
\text { Networks } \\
\text { techniques } \\
\text { bad they had } \\
\text { poor results } \\
\text { on other } \\
\text { datasets and } \\
\text { this problem } \\
\text { is due to not } \\
\text { enough } \\
\text { training and } \\
\text { also training } \\
\text { a very small } \\
\text { dataset and } \\
\text { results didn't } \\
\text { reach the } \\
\text { global } \\
\text { minima [10]. }\end{array}$ \\
\hline 2. & $\begin{array}{l}\text { P. Ralph } \\
\text { and J. } \\
\text { Parsons, } \\
2006 .\end{array}$ & $\begin{array}{l}\text { Authors } \\
\text { proposed a } \\
\text { framework for } \\
\text { automatic } \\
\text { online } \\
\text { personalization } \\
\text { through } \\
\text { recommendatio } \\
\text { n process and } \\
\text { they applied } \\
\text { some datasets } \\
\text { on several } \\
\text { artificial neural } \\
\text { network } \\
\text { techniques [11]. }\end{array}$ & $\begin{array}{l}\text { Authors work } \\
\text { did not } \\
\text { provide any } \\
\text { kind of } \\
\text { semantics to } \\
\text { provide the } \\
\text { automatic } \\
\text { discovery, } \\
\text { composition, } \\
\text { and } \\
\text { invocation of } \\
\text { those data } \\
\text { sets [11]. }\end{array}$ \\
\hline
\end{tabular}

\section{CONCLUSION}

Neural networks has a good significance improvement in elearning field such as personalizing user and learner needs by in finding the similarity of the domain concept data representation pattern between the student's and the learning object's profiles. We have discussed in our paper some applications of artificial neural networks in e-learning personalization since some years and discussed its significance and limitations in this field. 


\section{FUTURE WORK}

Future work may be by using different artificial intelligence techniques and neural networks together, Researchers could apply bigger and different datasets to deal with more eLearning applications. More extensive experiments should be conducted by using larger training and test sets. Many comparisons can be done between different AI methods for personalization results to check the performance of each method with considering reducing development, application time and cost.

\section{REFERENCES}

[1] Eldon Y. Li, "Artificial neural networks and their business applications" Institute of Information Management, National Chung Cheng University, Information \& Management Applications, Vol. 27, 1994, pp. 303-313.

[2] Matteo Gaeta, Sergio Miranda, Francesco Orciuoli, Stefano Paolozzi, Antonella Poce, "An Approach To Personalized e-Learning", SYSTEMICS, CYBERNETICS AND INFORMATICS volume 11, number 1, 2013.

[3] A. Baylari and G. A. Montazer, "Design a personalized elearning system based on item response theory and artificial neural network approach," Expert Systems with Applications, vol. 36, pp. 8013- 8021, 2009, http://dx.doi.org/10.1016/j.eswa.2008.10.080

[4] B.Yogesh Babu1 , G.V. Sriramakrishnan2, G.Visvanathan, "Survey of E-Learning: Content Personalization", International Journal of Advanced Research in Computer and Communication Engineering, Vol. 4, Issue 4, April 2015, DOI 10.17148/IJARCCE.2015.4474 328

[5] Hazem M. El-Bakry, Nikos Mastorakis, " Advanced Technology for E-Learning Development", RECENT ADVANCES IN APPLIED MATHEMATICS AND COMPUTATIONAL AND INFORMATION SCIENCES, Volume II, pp. 501-522.

[6]E Learning Engineering, http://www.elearningengineering.com/ai.htm, 2006.
[7] David J. Steinhart, "Summary Street: An Intelligent Tutoring System for Improving Student Writing Through the Use of Latent Semantic Analysis", Faculty of The Graduate School of the University of Colorado, 2001.

[8] SRI Consulting Business Intelligence, http://www.sricbi.com/Explorer/NN.shtml, 2004

[9] Mukta Goyal, Divakar Yadav, Alka Choubey, "Elearning: Current State of Art and Future Prospects", IJCSI International Journal of Computer Science Issues, Vol. 9, Issue 3, No 2, May 2012.

[10] Hassina Seridi, Toufik Sari and Mokhtar Sellami, " Adaptive Instructional Planning using Neural Networks in Intelligent Learning Systems", The International Arab Journal of Information Technology, Vol. 3, No. 3, July 2006, pp. 183-192.

[11] P. Ralph and J. Parsons, "A Framework for Automatic Online Personalization," Proc. 39th Ann. Hawaii Int'l Conf. System Sciences (HICSS '06), p. 137b, 2006.

[12] Pao-Hua Chou and Menq-Jiun Wu,"Accessing eLearners' Knowledge for Personalization in e-Learning Environment", Journal of Research and Practice in Information Technology, Vol. 41, No. 4, Nov. 2009.

[13] Ahmad Baylari and Montazer, Gh.A., "Design a personalized e-learning system based on item response theory and artificial neural network approach", Expert Systems with Applications, Vol. 36, 4, 2009, pp. 80138021.

[14] Norsham Idris, Norazah Yusof, and Puteh Saad, " Adaptive Course Sequencing for Personalization of Learning Path Using Neural Network", International Journal of Advance Soft Computer Applications, Vol. 1, No. 1, July 2009.

[15] J. Bernard et al., " Using Artificial Neural Networks to Identify Learning Styles", Springer International Publishing Switzerland, C. Conati et al. (Eds.): AIED 2015, LNAI 9112, 2015, pp. 541-544. 